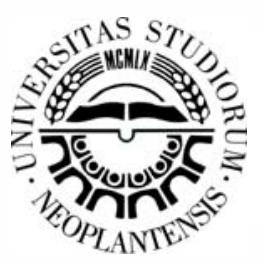

\title{
Improvements and materials for production of a magnetic drive micropump: an overview and recommendations
}

\author{
Ionut Ghionea $^{a^{*}}$, Constantin Opran $^{a}$, Saša Ćukovićc ${ }^{b}$, Mihaela Pleşa $^{a}$ \\ ${ }^{a}$ University Politehnica of Bucharest, Faculty of Engineering and Management of Technological Systems, \\ Bucharest, Romania \\ ${ }^{b}$ University of Kragujevac, Faculty of Engineering, Kragujevac, Serbia
}

\begin{abstract}
This paper presents an overview of an improved solution for an existing micropump model and, also, of the materials recommended to be used in the current stage of the prototype research. This micropump is provided with a closed system for driving and pumping the fluid, obtained by a special constructive solution, where the rotation of the motor shaft is provided by induction of a magnetic field.

The micropump system is composed by an external driving and an internal driven magnet, connected to a pair of gears that moves the fluid between the inlet and outlet apertures. These magnets are separated by a metal cover that provides a closed volume for the transported fluid with no need for supplementary sealing, as in the case of classical hydraulic pumps. Due to this constructive solution and to the applicative fields where these magnetic drive micropumps operate, their components are produced from compatible materials to provide a low friction/wear and high efficiency in use
\end{abstract}

Key words: micropump, magnetic drive, polymeric composite, polymeric, POM, PEEK;

\section{$1 \quad$ INTRODUCTION}

The magnetic drive pumps are, subjects of many research, design and manufacturing projects studied in industrial and academic environments due to their large applications in the fields of aerospace, automotive industry, medical systems, energy plants, food supply and refrigerate systems, consumer goods, etc.

Industrial customers need special hydraulic pumps, with a complex factor of innovation and variable functional parameters adapted to their requirements $[1,2]$. These pumps drive a specific fluid characterized by flow, pressure, viscosity, presence of particles, for various applications like: fuel transfer, injection and/or mixing of additives, dosing of substances in a medical installation, printing on textiles and ceramic tiles, etc. The magnetic drive pumps should be of a good constructive simplicity, reliability, very good sealing, low weight, small size and in a wide range of applicability.

The authors of the paper performed a research in the GEX
UPB project 57/2017 for the design and development of an innovative prototype of a magnetic drive micropump.

The project is about to identify and manufacture the best constructive variants of the magnetic drive micropump and to maximize its efficiency. Along with CAD/FEM modeling and simulation, the authors search for a combination of materials to manufacture the micropump's main components to provide these advantages over the classic pumps: high sealing, low wearing, compatibility with various fluids, manu-facturing solutions and costs. In the research, we intend to implement and use of polymeric composite materials for gears and suction element to reduce the wear resulted from the micropump operation. Also, for its body and cover some steel and aluminum alloys may be used in accordance with the composite materials of the gears.

The research project raises a number of challenges in all its phases: conception, design of the selected ideas, numerical and technological simulations [3], which will contribute to generating and expanding new knowledge into industrial

* Corresponding author's.e-mail: ionut.ghionea@imst.pub.ro 
environment. The documentation phase of other solutions (constructive and materials) in this field of magnetic drive pumps is very important.

\section{SCIENTIRC ANDINDUSTRIAL REEVANCE}

Generally, the magnetic drive pumps have various components made of steel, composite and polymeric materials. They are important for industry because their need for industrial application is growing every year. The innovative development of new prototypes is based on the scientific research, calculus, simulations and tests. There are considered: the conception and development of new models, the improvement of existing ones, the identification of new materials that can be used for their components according to purpose and to the fluids driven in specific hydraulic installations. Thus, a research team should consider: a low number of components, based on a relatively simple configuration, volumetric characteristics $[4,5]$ calculated and parame-terized using CAD software, a very good efficiency, a good wearing resistance of the components, the possibility of cooling the pump under certain stress conditions, possibilities of manufacturing certain components with composite materials adapted tofunctional requirements, bi-directional transfer, fast response to fluid flow, low maintenance, fast replace-ment of worn components, etc.

The biggest challenge of the proposed research is to design the pump prototype, optimize the choice of metallic and polymeric composite materials for its components, to apply specific manufacturing and assembly technologies. Due to various constraints imposed by beneficiaries, the materials used for its components should provide perfect operation in harsh environments, at temperatures over $100^{\circ} \mathrm{C}$, with corrosive fluids such as sulfuric acid and hydrochloric acid, chlorine or various chemical solutions. Generally, fluid losses during the operation of a hydraulic pump are an important issue for the hydraulic installation, for the environment, especially for hazardous, expensive fluids or those not to be contaminated from the outside. Of course, despite these constraints, the project's cost should be optimal and the resulted prototype reliable and affordable for mass industrial production.

Conception and development of a new magnetic drive pump rises some risks: the magnetic field creation system required to drive the pump may have a high energy consumption; high costs for experiments and validation of the pump variant; dissipation of the magnetic flux inside the pump without a proper driving effect [1]; certain functional requirements [2] may not be fulfilled by the functional prototype, leading to a decrease of the prescribed pressure and the appearance of certain worn areas; the choice of the metallic and polymeric composite materials may require further laborious researches; difficulties in balancing the resulting forces from pump operation [6], etc.

\section{WHY TOUSE MAGNETICDRIVE PUMPS?}

A standard pump requires solution of sealing necessary to stop the driven fluid from leaking out around the pump shaft, especially when it is at high pressure. There are some constructive variants to prevent this leaking, thus: a soft packing material compressed around the pump shaft in the pump's casing; a lip seal or an O-ring that is a rubber or plastic ring fitted around the drive shaft and held in place in a recess in the pump housing; a mechanical seal that consists of two parts: a stationary component attached to the pump housing and a second, rotating component on the pump shaft. The faces of the two components are manufactured to be flat and smooth and are pressed by springs to keep them together. This is the most effective option, but may be expensive and difficult to apply, especially in the case of small pumps or in the transfer of high pressure fluids [7]. Even by using expensive solutions, the leakage cannot be fully eliminated. It is important to maintain a small leakage to lubricate and cool the seal and the pump shaft that exits the pump being connected to a motor [5].

Often, it is necessary to add an external lubricant to avoid wear/overheating and this creates the unwanted chance of contamination of the driven fluid. Also, any pump seal needs to be monitored and maintenance to prevent excessive leakage, particularly when the driven fluid is toxic, medical, flammable or environmentally dangerous. Some of the leaked fluids may have to be isolated, contained and disposed of safely, with important costs and additional constructive solutions.

Leakages are one of the main causes of standard pumps failures or shutdowns of the hydraulic installa-tions. The monitoring and maintenance of standard pumps is expensive and time-consuming.

Environmental concerns pushed the research teams to conceive a cleaner pumping technology and to implement magnetic drive pumps that contains the fluid completely inside the housing. These pumps have a hermetic seal, a stationary gasket or O-ring, that is not in contact with moving parts. This seal is therefore wear-proof and the pump can be used in applications where no leakage is highly required.

\section{PROPOSED MODE OF A MAGNETIC DRIVE MCROPUNP}

In this research project we focused on improving an existing hydraulic gear micropump with helical teeth. We made some constructive and functional changes, due to the wear appeared on some of its components. The wear has been observed at the arrival of the micropump (Fig. 1) at our university Composite Products Laboratory provided by the service department of the Axflow Romania. The pump is withdrawn from the service, its type is GB-P25.JF5S.A, by Micropump Inc. [8].

According to the manufacturer specifications, the pump flow rate varies between $Q p=1.65 \div 3.11 / \mathrm{min}$ corresponding

to the drive speed variation of $n=2850 \div 5500 \mathrm{rev} / \mathrm{min}$. This micropump can generate a maximum pressure of 8.6 
bar, and it can uphold a maximum pressure of 21 bar. The temperature during its operation may vary in the range of $46^{0}$ to $177^{0} \mathrm{C}$. The viscosity of the hydraulic medium may be of $0.5-1500 \mathrm{cp}$ [8].

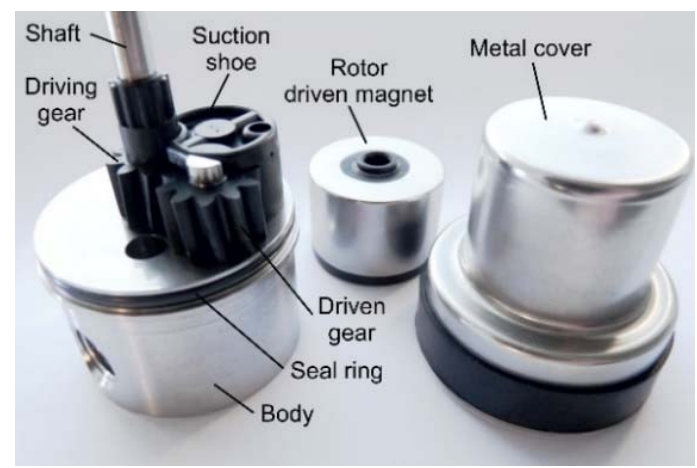

Fig. 1 Disassembly of the magnetic drive micropump

Following the pump's driving under laboratory conditions and testing with a fuel fluid (characteristics in the range prescribed by the manufacturer), it was noted an increase in the drive torque (by 12-18\%) and a pressure variation, due to the damaged worn areas.

The areas with the most pronounced wear (Fig. 2) are located on the body's flat surface around the two shafts: under the driving and the driven gears (W1 and W2). There was also observed an increased wear of the pinion's shaft due to the forces in the gear. The worn areas led to an increase of gearing forces and to a deficient contact between the teeth flanks. At the same time, there we remarked vibrations, noise and heating inside the micropump during operation.

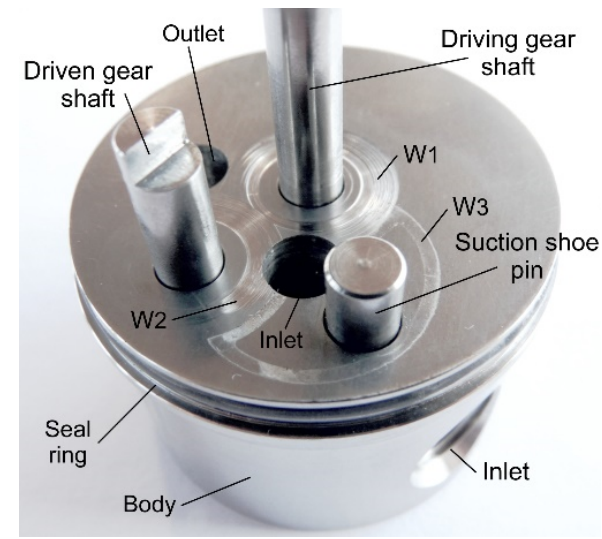

Fig. 2. Fixed parts and different areas of the micropump

The micropump has a suction shoe to guide the fluid into the micropump to be placed in the gaps between the teeth, driven and discharged through the outlet aperture [8]. There is also a wearing zone W3 in the contact area between this suction shoe and the flat surface of the body due to the vibrations resulted from the operation.

In a previous paper [9] we presented 3D modeling phase (Fig. 3) and proposed innovative and constructive solutions to improve the characteristics of this micropump. The most important modification was to replace its pair of gears with the new corrected (displaced) helical gears, but with another module size, offering an increase of the micropump's flow, at the same distance between the shafts and same drive speed.

Another innovative change on the original micropump assembly is the design of a new suction element to separate the aspiration zone of the fluid by the driving gear through the inlet port to the outlet port. Thus, a significant reduction in torque is required to drive the fluid from the entire cavity under the metal cover. So, the vibrations, noise and wear will be significantly reduced. The fluid inside the micropump's cavity, under the cover, between the inlet and outlet ports, is still trained by the driven gear to ensure the lubrication [10], but at a smaller rate.

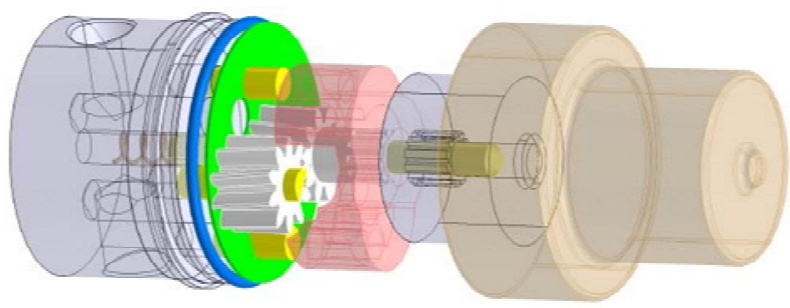

Fig. 3. 3D model of the proposed micropump

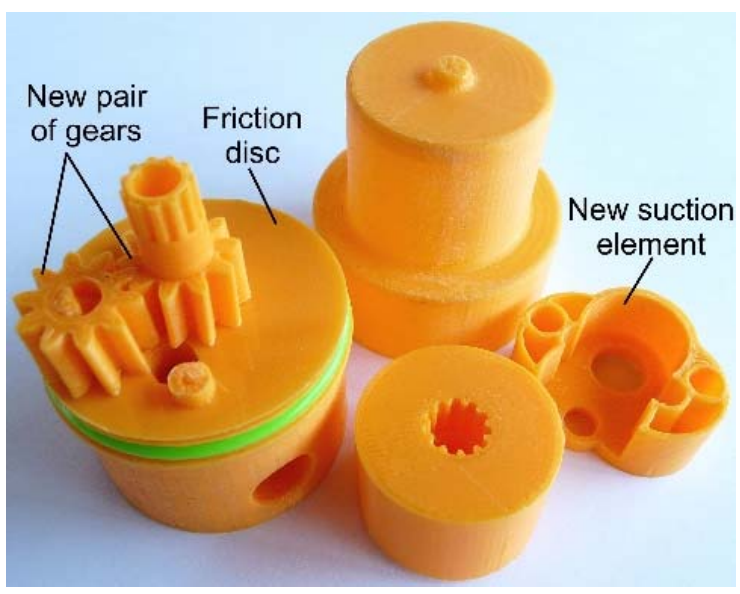

Fig. 4. 3D printed prototype of the modified micropump

The 3D model of the proposed micropump is completed by a friction disc assembled in contact with the flat surface of the body. This variant was conceived and designed [9] in CATIA v5 and 3D printed (Fig. 4) to verify the gearing, positions and compatibility of the new suction element and of the friction disc with the unmodified components of the micropump. The friction disc is provided with holes for mounting the gears shafts, the two pins that support the new suction element and the inlet and outlet holes (Fig. 2). This disc bears the wear of the micropump body's flat face in the improved version and it is simple to be replaced, if needed, during service and maintenance intervals. Through its flat surface, the disc can also be used with actual micropumps, still in service, that have an acute wear of the body, to increase their lifetime and operation. 


\section{MATERIALS USED FOR THE MCROPUMP'S COMPONENTS}

Our new micropump model needs a confirmation of current materials selected or new ones. The wear observed on the micropump (Fig. 2) in our laboratory resulted from the long contact of the gears and the suction element with the metal components (body and driving gear's shaft).

In the company's documentation for this model, the gears and the suction shoe element are made of PEEK (PolyEther Ether Ketone) because it is a high-performance engineering plastic with great resistance to chemicals, solvents, fuels and additives, with an excellent mechanical strength and dimensional stability. It is neutral to steam, water and salt water. PEEK has also the ability to maintain the parts stiffness at high temperatures up to $170^{\circ} \mathrm{C}$. The main benefits of gears made of PEEK over metal gears are: up to $70 \%$ weight reduction, up to $50 \%$ noise reduction and up to $80 \%$ reduced moment of inertia [7]. The reduced weight and moment of inertia are necessary for the operation of this micropump driven by magnets.

According to [11], Victrex PEEK polymers maintain mechanical properties at high temperatures and in adverse chemicals and moisture, making them the material of choice over other gear materials to the industry demands for extended service life in various challenging environments. Victrex has created a new PEEK for use in gears applications improving the already proven properties of Victrex PEEK 450G to achieve better performance. Based on the literature review [2, 9, 12], we recommend this material for the micropump's gears because of a low energy consumption (gears result with an important weight reduction), less vibrations and noise, a reduced moment of inertia leads to improved responsiveness, simplicity in mass production (by injection-molding process) with no other machining and/or finishing operations, easy to be integrated in hybrid technology with composites, metals and other plastics, etc.

We also recommend for gears, the suction shoe element and the friction disc to be produced of the POM (Polyoxymethylene) material. For this micropump we propose the use of Ultraform [13], a co-polymeric POM created by the BASF company with excellent mecha-nical properties (strength, toughness, fatigue endurance, low tendency to creep), surface hardness, resistance to wear, moisture and chemicals. It can be processed rapidly by extrusion and injection molding, without deposits and are also easy to demold, with a very good surface quality.

For the metal components of the micropump, the 316 or 304 steel types [14] can be retained, as in the current micropump. They are austenitic chromium-nickel stainless steels containing molybdenum, that increases general corrosion resistance, improves resistance to pitting from chloride ion solutions and provides increased strength at high temperatures. These steels have also an improved corrosion resistance against hydrochloric, sulfuric, acetic, formic and tartaric acids, acid sulfates and alkaline chlorides.

\section{Conclusions}

This paper is part of the research project for creating new and/or improving actual magnet drive micropumps to increase their performance, lifetime and optimizing their maintenance. Changes proposed refer to a new constructive solution with a new pair of gears to raise the micropump's flow, but also to the concerns to reduce the wear of its components. Along with dimensional or shape changes of the components, the materials used are very important because of the micropump's role and fluids pumped in the hydraulic installations.

Gears have a very important role in pumping the fluid with good efficiency, they need a low maintenance, so their life can be maximized by selecting a polymeric material suitable to the hydraulic medium. This material should balance friction and wearing properties, flanks surface quality, strength and fatigue resistance at high operating temperatures. The plastic gears are light-weight, easy to manufacture by injection molding at low cost and large production, non-rusting and able to operate without lubrication by mating with proper metal gears and/or other of the pump's components.

However, in certain conditions (viscosity, high flow or pressure, presence of particles etc.), these gears may prove to have low strength, tendency to hold heat, become worn too fast and not functional compared to metal gears [7].

Future research in the field of this type of micropumps will include the redesign of the body and the metal cover to add and ensure the mixing and dosing functions of two compatible fluids to pump them into the hydraulic system. It is also expected a complex study for the parameterized creation of a micropump family to provide a wider range of flows and pressures and the possibility to flow fluids with different viscosities.

\section{ACKNOMFDGEMENTS}

This work has been funded by University Politehnica of Bucharest, through the "Excellence Research Grants" Program, UPB - GEX 2017, Ctr. No. 57/2017.

The authors wish to thank AxFlow Romania for providing the micropump and the necessary documentation for this research. This work is also in the frame of the PhD thesis: Researches on the manufacturing flux of constant flow hydraulic pumps to improve the technical and economical performances, $\mathrm{PhD}$ supervisor: Full Prof. Adrian Ghionea.

\section{REFERENCES}

[1] Ghionea, I., Opran, C., Tarbă, I., Tiriplică, P., Magnetic drive pumps. Current state and overview, Scientific Bulletin, Serie C, Tribology, Machine Manufacturing Technology, pp. 79 - 82, 2017.

[2] Rundo, M., Models for flow rate simulation in gear pumps: A Review, Journal of Energy Research, Engineering and Policy, 2017. 
[3] Rajeshkumar, S., Manoharan, R., Design and analysis of composite spur gears using finite element method, IOP Conference Series: Materials Science and Engineering, no. 263, IOP Publishing, 2017.

[4] Borghi, M., Zardin, B., Specchia, E., External gear pump volumetric efficiency: Numerical and experimental analysis; SAE Technical Paper; SAE International: Warrendale, USA, vol. 2(1), pp. 1285 $-1302,2009$.

[5] Ghionea I., Ionescu, N., Ghionea, A., Ćuković S., Tonoiu, S., Catană, M., Computer aided parametric design of hydraulic gear pumps, Acta Technica Napocensis, Applied Mathematics, Mechanics and Engineering, Technical University of Cluj-Napoca, vol. 60, no. I, pp. 113-124, ISSN: 1221-5872, WOS: 000416959000017 , Cluj-Napoca, Romania, 2017.

[6] Opran, C., Ghionea, I., Pricop, M., Embedded modelling and simulation software system for adaptive engineering of hydraulic gear pumps, Proceedings of the 26th DAAAM International Symposium, pp. 0311-0319, DAAAM International, ISSN 1726-9679, Vienna, Austria, 2016.

[7] https://www.michael-smith-engineers.co.uk/ resources/ useful-info/magnetic-drive-pumps

[8] Magnetic drive gear pump, GB series, GB EagleDrive, Micropump Inc, 2018.

[9] Ghionea. I., Opran, C., G., Ghionea, A., Ćuković, S., Tarbă, C., I., Adaptive design of a 3D model magnetic drive micropump for an extended life cycle and low maintenance, Acta Technica Napocensis, vol. 61, issue 2, Applied Mathematics, Mechanics and Engineering, Technical University of ClujNapoca, ISSN: 1221-5872, pp. 201-212, WOS: 000437045000008, , Cluj-Napoca, Romania, 2018.

[10] Meng, H., Sui, G., Xie, G., Yang, R., Friction and wear behavior of carbon nanotubes reinforced polyamide 6 composites under dry sliding and water lubricated condition. Composites Science and Technology, vol. 69, pp. 606-611, 2009.

[11] https://www.victrex.com/en/victrex-peek

[12] Pogačnik, A., Kalin, M., The running in phase of polymer materials for gears, Centre for Tribology and Technical Diagnostics, University of Ljubljana, Slovenia, 2017.

[13] Ultraform ${ }^{\circledR}$ (POM) Product brochure, BASF company, 2017.

[14] 316/316L Stainless steel, SAE grades, 2017. 